\title{
The influence of collaborative language learning on cognitive control in unbalanced multilingual migrant children
}

\author{
Martha Gilmore Robinson $^{1}$ • Antonella Sorace ${ }^{1}$
}

Received: 9 May 2017 / Revised: 9 March 2018 / Accepted: 14 March 2018 /

Published online: 5 April 2018

(C) The Author(s) 2018

\begin{abstract}
In this study, (N62) 5- to 6-year-old English monolingual and unbalanced multilingual children attending public primary school education in Scotland became involved in collaborative Narrative Format (Taeschner, 2005) modern language activities in Spanish, both at school and at home. These activities were redesigned and adapted to serve as a quasi-experimental tool to provide a highly structured and intense linguistic input. The main purpose was to explore whether cognitive advantages previously found in balanced bilinguals and second-language-learning monolingual children involved in language immersion programmes could be extended to different types of beginning language learners in a non-immersion context. Depending on the monolingual vs bilingual ratios of children in the classroom, we distinguished between homogeneous groups (characterised by a ratio of $95 \%$ of first-language English-language monolinguals) and heterogeneous groups (children from both Scottish and migrant homes in roughly equal proportions). Using a standard task of early cognitive control, we found not only that unbalanced multilinguals perform above chance but also that there was a developing trend of enhanced performance for monolinguals learning languages in the heterogeneous groups. This suggests that not only the length of exposure and intensity of input but also the social classroom environment where children develop their language skills may also play an important role in the effects of bilingualism on executive functions.
\end{abstract}

Keywords Unbalanced bilingualism · Input - Cognitive development $\cdot$ Non-immersion language education

Martha Gilmore Robinson

martha.robinson94@gmail.com

1 PPLS, University of Edinburgh, Edinburgh, Midlothian, UK 


\section{Background}

Research has shown that bilinguals often outperform monolinguals in cognitive control tasks tapping different aspects of executive function (Bialystok 1999; Bialystok and Martin 2004; Bialystok and Feng 2009; Luk et al. 2011; inter alia). However, the exact conditions under which these benefits develop are still a matter of ongoing research, especially since a number of studies have failed to replicate the effects (Paap and Greenberg 2013; Paap and Sawi 2014; Paap et al. 2014; inter alia). One often-mentioned cause at the source of this advantage for bilinguals is the experience of inhibiting one language when using the other and switching between languages as bilinguals engage with different interlocutors in different contexts. The wide range of variation across bilingual environments may be one of the reasons why the effects of bilingualism are not visible in all contexts (Green and Abutalebi 2013). Another important open question addressed by researchers is the specific time frame and conditions for the emergence of these effects. As bilingualism may be shaped by different experiences, it is not clear how long and how much time individuals might need to be exposed to secondlanguage (L2) linguistic input before significant effects emerge (Poarch and van Hell 2012).

Studies in this area mainly involve bilinguals of the balanced type, and one of the oftenmentioned conditions for the emergence of cognitive benefits is the associated fact that individuals show high levels of proficiency in both languages. De Houwer (2009) points out that proficiency in each language for bilingual children is directly related to their relative exposure to their respective languages. In other words, high levels of proficiency correlate with high levels of linguistic input from a variety of direct and indirect sources. This is what was investigated in Place and Hoff (2011) with groups of English-Spanish bilinguals using the language diary method developed by De Houwer and Bornstein (2003). In this study, caregivers kept a detailed log of children's language exposure over the course of seven days in different communicative contexts; it was found that the family practices had a great impact on the type of input received by the children. The attainment of proficiency in their home language was closely linked to interactions with different members of the family, friends or even other sources of indirect linguistic input (like TV programmes, music and books). However, as argued in Unsworth (2014, 2016a), what matters is not only the quantity of input in terms of number and types of sources but also its quality. One factor affecting possible input quality is whether individuals are exposed to input from native or non-native speakers. It is often the case that bilingual children are exposed to input from both, and predominant exposure to non-native speakers might not be as effective a tool to support language acquisition. Although as yet not completely understood, one of the reasons adduced is that nonnative language is often associated with lower levels of language proficiency and children might not be exposed to the whole range of explicit (grammatical, phonological, lexical, etc.) and implicit (pragmatic) features that constitute the knowledge that native speakers typically have of their language.

Another factor also highlighted in Unsworth (2016a) which might have an impact on the bilingual/multilingual child's language experience is the amount of language use (or 'output') and the associated differential processing skills required by using language in production, rather than simply decoding it in comprehension. However, as this author also notes, how this relates to cognitive development is not properly understood yet and is still a matter of ongoing research. One aspect tapped into by research in this area is the development of the Theory of Mind and executive functions. For example, in a study by Sabbah et al. (2006) involving preschool children from both China and the USA, it was found that the Chinese children 
performed better on tasks tapping into executive function than the American children. It was suggested that this success might be related to cultural differences in parenting goals, especially in controlling child behaviour. As most research supports the idea that the emergence of cognitive effects is related to the intensity of language switching and cognitive control, it is still an open question whether different parenting styles, family dynamics or cultural differences play a role (Deák 2014). Moreover, it is often the case that contributing factors such as age of onset of language learning and testing, education and language combination patterns, among others, are not always interpreted alongside as possible variables (Garraffa et al. 2015). Therefore, the more practical and fundamental question relevant to the current study is whether it is possible to replicate the bilingual experience in a classroom setting and, as a result, whether children are able to accrue cognitive benefits despite the limited opportunities for language use and interaction which characterise traditional non-immersion language learning experiences at school.

\section{Cognitive benefits and language immersion education}

There are several studies concerned with cognitive benefit attainment in classroom settings that involve second-language immersion programmes. Typically, in these types of settings, languages are not taught specifically, but rather they are used as a medium of instruction for academic subjects and students learn languages indirectly from the classroom communicative context. The results in these studies have been mixed and not always completely comparable, although bilinguals tend to show a general advantage over monolinguals. For example, Carlson and Meltzoff's (2008) study involving late 4- to 7-year-old children (M age $=6.2$ years, $\mathrm{SD}=5.68$ months, range $=4.8-7.3$ years: 26 boys, 24 girls) compared bilinguals and monolinguals taking part in a language immersion educational programme at the kindergarten level for 6 months with control monolinguals: the results showed that bilinguals outperformed both groups of monolinguals and, crucially, that there was no visible difference between the monolingual groups in terms of attainment of cognitive benefits. One possible factor highlighted in Bialystok et al. (2014) in relation to Carlson and Meltzoff's (2008) study is age: the children in both monolingual groups might have been too young to show any real effects, as these effects are closely intertwined with other developmental aspects and tend to be gradual by nature and, as a result, there is a great deal of individual variation within this age group. In fact, a later study by Nicolay and Poncelet (2013) suggested that the crucial factor for the emergence of cognitive effects is length of exposure to linguistic input, rather than age. In their study, 8-9-year-old monolingual French-speaking children who had been involved in an early English-based immersion education programme for a period of 3 years showed faster reaction times than monolingual controls on tasks assessing alerting, selective auditory and divided attention and flexibility. In contrast, no difference between these two groups was found on response inhibition or interference inhibition tasks. An important difference between this study and that of Carlson and Meltzoff was not only in terms of length of exposure but also possibly in terms of different input experiences, and individual children were unable to reap the linguistic and cognitive benefits. In contrast, the language exposure in Nicolay and Poncelet's (2013) study was highly structured throughout the 3-year duration of the immersion programme, with activities specifically designed to support and accelerate language learning, which enhanced input exposure in terms of quantity and quality. Therefore, it is not surprising that these children showed mixed results despite the fact that their English language 
proficiency levels were lower than would have been expected for bilingual children of the balanced type. However, one frequently mentioned shortcoming associated with the immersion language learning experience is the unbalanced production rate among individuals, which is in turn related to the difficulty of monitoring the type and style of communicative interactions taking place (Poarch and van Hell 2012). Nevertheless, the main insight gained from the above-mentioned studies is that if the length of exposure is sufficient, even unbalanced bilinguals can benefit cognitively from the bilingual experience.

\section{Cognitive effects and non-immersion language learning}

Some recent studies suggest that the benefits found in language immersion education can also be extended to non-immersion education programmes. For example, in a study involving children attending a more traditional non-immersion type of language education, Poarch and van Hell (2012) studied different groups of speakers with different levels of English language proficiency and language learning backgrounds (6- to 8-year-old German-speaking monolingual controls and 5- to 8-year-old German L2 learners of English, German-English bilinguals and German-English plus additional language trilinguals). Their study showed there was a slight advantage for L2 learners over monolingual controls, which differed across groups: bilingual and trilingual speakers showed enhanced conflict resolution abilities over monolinguals, but most importantly, non-immersion L2 classroom learners of English showed a marginal advantage over monolinguals too. This result once again highlights the fact that bilingualism/multilingualism is not categorical, but gradient, because it can be shaped by different kinds of experiences; consequently, no two bilingual individuals can be regarded as being identical as their language learning experience can be modulated by many covert and overt factors. It is against this background that the need emerges for more fine-grained studies on language learning and cognitive consequences at the lower ends of the language proficiency spectrum.

\section{The current study}

Our study addressed the question of whether the cognitive effects of language learning could be replicated with different types of monolingual and unbalanced multilingual children involved in early L2 learning in a non-immersion classroom setting. We studied a group of children aged 5-6 $(\mathrm{M}$ age $=5.34, \mathrm{SD}=0.43$, range 5.00-6.05) attending public schools in socially disadvantaged areas in Edinburgh. These children formed part of a cohort of 523 children who were involved in the wider European School and Family Together for the Integration of Migrant Children (SOFT) project, which was conducted in 6 primary schools in Edinburgh. Earlier research had shown that speaking minority home languages does not contribute to academic underachievement (see Cummings 2012 for a review on this issue); therefore, an important aspect of this project was the encouragement of migrant families to retain their home language. In addition, a second aim of the project was to encourage early uptake of language learning for home students. Across the whole project, children could learn either French or Spanish as a modern language; however, the children selected for our study were the ones involved in Spanish activities. 
Although some previous studies involving language immersion programmes reported marginal cognitive effects for L2 monolingual speakers (Nicolay and Poncelet 2013), one important shortcoming is that none seemed to have taken the particular classroom dynamics into consideration, especially the monolingual vs multilingual child ratios in the classroom. Since an essential aspect of the multilingual experience for children growing up in this type of environment is that they are exposed to other multilingual individuals in different family types and communicative contexts (Nicolay and Poncelet 2013), we wanted to know whether different groups of speakers from a range of social settings would draw the same benefits from the language learning experience. Therefore, depending on the migrant/Scottish child ratios in the classroom, the participant groups in the schools involved were classified as belonging to two types: homogeneous and heterogeneous groups. Homogeneous groups typically had a ratio of $95 \%$ of L1 English monolinguals. English was the main language in the classroom, and all the children were engaged in second-language activities in Spanish with the Narrative Format Methodology. Heterogeneous groups, in contrast, included children both from Scottish monolingual homes and from migrant monolingual as well as multilingual families (roughly $50 \%$ mono- and multilingual children).

Monolingual English L1 speakers in heterogeneous groups were learning Spanish from collaborative language activities taking place in the classroom and at home. Multilinguals in heterogeneous groups, in contrast, were exposed to three languages: their home language, English from their school community and Spanish with the same language learning methodology as their monolingual heterogeneous counterparts.

In the multilingual group, a high number of children had a very limited level of English language proficiency as they had recently arrived in the country. Many of these children were monolingual speakers of immigrant home languages who were in the incipient stages of becoming bilingual and were engaged in structured school activities in English. By definition, they were exposed to both native and non-native speakers of English. The classroom setting itself replicated a typical multilingual experience where both mono- and multilingual individuals interact in context and engage in communicative activities, while at the same time learning other languages.

Language learning took place both in the classroom with the teacher and a tutor (who was a native speaker of Spanish) and at home with the families. The main aim was to replicate a naturalistic language learning experience in quasi-experimental conditions, but the learning environment created a highly intensive input learning experience for both monolinguals and multilinguals. The programme was specifically designed to develop comprehension skills, and although language production was limited to repetition, children were able to engage in structured dialogues as part of the interaction established through the Narrative Format Methodology (discussed in more detail below), which ensures that elements of communication such as eye contact and turn taking were strictly adhered to.

Previous studies have shown that the bilingual advantage tends to be manifested in tasks involving conflict resolution (see Bialystok et al. 2014 for a review). As the nature of our study was mainly exploratory, we decided to use only one of these tasks as cognitive measure: the Dimensional Change Card Sorting task (Zelazo et al. 1996). Evidence from previous research shows that cognitive control and executive functions cannot be interpreted as a discrete category as children develop them at different rates. Therefore, as the children involved in our study were still within an age range where executive functions are still developing, we chose to focus on a narrow age span of 5-6 years. 
Our research was driven by two questions: the first was a more general one concerning the monolingual/multilingual distinction in a non-immersion language programme: can cognitive effects of bilingualism be found in different language groups (monolingual vs unbalanced multilingual speakers) in an intensive non-immersion language learning environment?

The second question specifically concerned the group of English L1 monolingual speakers: do the group dynamics established within different classroom settings with regard to the presence or absence of other multilingual individuals (i.e. the homogeneous vs heterogeneous group distinction) favour the emergence of cognitive effects?

\section{Method and materials}

\section{Participants}

A total of 62 children aged 5 to 6 years ( $M$ age $=5.34$ years, $\mathrm{SD}=0.43$ months, range $=5.00$ 6.05 years, 32 girls and 30 boys) who were L1 English monolingual $(N=36)$ and unbalanced bilinguals/multilinguals learning English as a second language $(N=26)$. All the children were attending Primary 1 education. Although the overall project involved six primary schools, two of them were excluded, because the groups who took part involved younger children (4-5-yearolds). In addition, these groups also contained too many multilingual children who either spoke English at home or had been born in the UK and a great number of them had the same Polish linguistic background. As we wanted to ensure that participants had had limited experience of language switching, we chose the groups with more heterogeneous language experiences. The linguistic and cultural backgrounds of the multilingual children selected included Brazil, China, Iraq, Italy, Nigeria, Poland, Portugal, Slovakia, South Africa, Spain, Syria and Zambia. As Cummings (2012) mentions, it is often difficult to assess proficiency in home languages for linguistically heterogeneous groups, since in many cases equivalent assessment tests are nonexistent. Therefore, as the children formed a culturally and linguistically heterogeneous group, we were not able to assess proficiency in their individual home languages quantitatively in a direct manner. Instead, we administered a Linguistic Habits in the Home Questionnaire (LHHQ) created to gather qualitative data on family background information such as types and numbers of speakers and other direct and indirect sources of input the children were exposed to at home. Crucially, this questionnaire helped to identify families who had recently arrived in the UK and established whether English was spoken in the home. In order to be certain that the children had had limited experience of language switching, we selected the ones who did not speak English at home. Proficiency in English was calculated from the combined standardised scores obtained from the British Picture Vocabulary Standard (BPVS3).

This group of children were labelled as heterogeneous L2 in Table 1. L1 English monolinguals, in contrast, where further subdivided according to whether they were involved in a homogeneous group $(N=22)$ or a heterogeneous group $(N=14)$, labelled as homogeneous L1 and heterogeneous $L 1$, respectively, also in Table 1.

Table 1 shows that all three groups are mostly matched for age but differ in terms of proficiency, and this is especially noticeable for the unbalanced multilingual group, who were on the low side of the proficiency spectrum. In fact, a great number of them showed very limited or no English at all. Although our measures here were based on standardised scores, our heterogeneous L2 children's raw proficiency scores at 5-6 years old in English were matched with Nicolay and Poncelet's (2013) 8-year-old French-speaking monolingual children 
Table 1 Ages and English language proficiency characteristics of participants by group (means and standard deviations in parentheses)

\begin{tabular}{llll}
\hline & Homogeneous L1 & Heterogeneous L1 & Heterogeneous L2 \\
\hline Age & $5.2(0.34)$ & $5.4(0.49)$ & $5.4(0.45)$ \\
English proficiency & $\mathrm{M}=103(13.47)$ & $\mathrm{M}=93.07(14.55)$ & $\mathrm{M}=81.68(10.66)$ \\
Language group & English monolingual 1 & English monolingual 2 & Multilingual \\
\hline
\end{tabular}

in English language immersion education: with 3 years difference, Nicolai and Poncelet's older L2 English immersion children matched our younger unbalanced multilingual children in terms of proficiency measured with the equivalent American Peabody Picture Vocabulary Test (PPVT3); as mentioned above, it was these L2 English-learning children who showed a marginal advantage. An important question raised here is whether the non-immersion younger children with lower levels of proficiency in this study would also show any significant cognitive effect of language learning. We took the homogeneous L1 English monolingual children to be our control group, and both heterogeneous L1 and L2 constituted our experimental groups.

\section{Procedure}

The schools involved in the project were selected directly by educational authorities in Scotland, and information events for parents were organised at each school at the beginning of the project. Written informed parental consent for participation in the project and testing were obtained through standard official procedures set in place at individual schools. At the end of the project, teachers, families and educational authorities were also informed of the results at a general debriefing event. The study was approved by the Linguistics and English Language ethics committee at the University of Edinburgh.

All the children tested were involved in Narrative Format activities in Spanish. The children were involved in the study for the duration of one school year and were selected by the class teachers, ensuring that they were matched for age and abilities. They were tested twice, once at the beginning of the programme and then 6 to 8 months later for a second time, in order to allow for intervening school activities and short holiday periods.

Individual testing took place either in a quiet separate spot in the classroom during the course of daily lessons or in a separate room in the school. Testing sessions lasted for about 20 min per participant, and the tasks administered were the British Picture Vocabulary Standard (BPVS) and Dimensional Change Card Sorting Task (DCCS), Standard and Border versions (Zelazo et al. 1996), a quick and easy-to-administer conflict resolution task which requires minimal disruption to the children's daily routine.

As part of background measures, as mentioned earlier, we administered a Linguistic Habits in the Home Questionnaire (LHHQ) handed out at the information meetings organised in schools at the beginning of the project.

\section{Language learning activities}

Children were exposed to Spanish language activities in the classroom for the duration of one school year. The basic underlying principle of the Narrative Format Methodology is that children acquire a second language immersed in social communicative interactions situated in 
engaging contexts. This type of approach is consistent with usage-based theories (Tomasello 2003; Goldberg 2003; Abbot-Smith and Tomasello 2006; inter alia) that describe language acquisition as a process of abstracting linguistic information from experience. These everyday communicative interactions were embedded into six narratives, called formats in this methodological approach (a sample of format 1 can be seen in Appendix).

They depicted the adventures of two fictional characters - the Hocus and Lotus Dinocrocs - as they move through everyday child-oriented situations. The stories were presented in different modalities such as cartoons, CDs or e-books which facilitated situational and lexical contextualisation and provided exposure to the main phonological features of Spanish. These additional materials were provided to the schools for free, and the children were able to take them home and share them with their families. However, the most important component of this collaborative language learning approach was a highly ritualised and interactive activity consisting in acting out these stories in the classroom by a trained tutor together with the children and the classroom teacher. The acting out involved gestures and expressive talking and singing. The tutor was trained through a series of intensive workshops organised by the international coordinators of the project, who facilitated specialist training in the Narrative Format Methodology. The sessions included language-specific training on the performance of the narratives (or formats), as well as more general methodological issues. In turn, the tutors in their own countries also organised independent training sessions with the teachers involved, to ensure they were familiar with the basic philosophy and dynamics of this methodology. The role of the tutor was crucial as she fulfilled a double role of performer and trainer, and her direct involvement ensured that the acting-out activity was delivered consistently to the children on a weekly basis in the same way every time. Each narrative was worked upon for 4 weeks at a rate of approximately one story per month. When the trained tutor was not present, teachers and children read and acted out a reduced version of the stories which provided the basic narrative frame in the shape of a pictogram (Fig. 1). This provided constant repetition of the main essence of the stories and gave children the confidence for the main acting-out activity with the tutor. Children were also engaged in other collaborative learning activities both at home and in the classroom, such as the creation of dedicated play areas for the classroom recreating the principal elements in the stories, the construction of props and creative projects which afforded ample opportunity for repetition of linguistic structures and implicit learning processes.

Although these narratives exist independently as a commercial product, we used them as a quasi-experimental tool and designed and adapted them in such a way as to provide a highly structured and intensive kind of input for the purposes of the study. The six narratives provided a 4683-word learning corpus and were modified with the aim of providing a good balance between grammatical and lexical features, as well as both high- and low-frequency lexical items.

\section{Measures}

\section{Background measures}

Linguistic habits in the home questionnaire This questionnaire was designed as a parental report to gain information about individual participants such as age and birthplace and to determine whether the English language was spoken in the home. Another purpose was 


SOFT-Activities
1. Hocus en el parque... para leer y aprender el
vocabulario con los gestos.

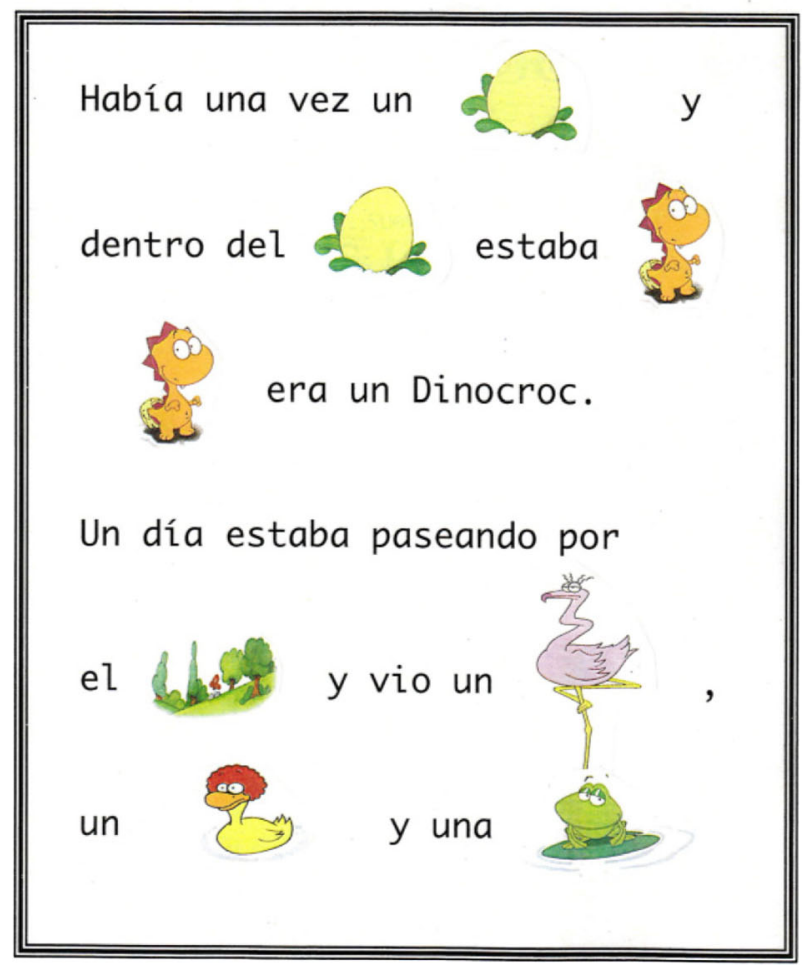

Fig. 1 Sample of pictogram for format 1

to monitor the children's home language background and language use with questions concerning time scales and age of acquisition, range of interlocutors and more general proficiency.

It was designed specifically for the purposes of this study, but it was loosely based on The Bilingual Language Exposure Calculator (BILEC) (Unsworth 2016b).

Although in its original form BILEC is a digital questionnaire, for practical reasons, we provided a hard paper copy, because not everyone involved in the study was proficient enough in the use of computers or had access to one at home.

BPVS3 This is a measure of British English receptive vocabulary (Dunn et al. 2009) and was used as an indicator of English language proficiency. For each word assessed by the experimenter, a page divided into four coloured pictures was shown and children were asked to choose one which best described the word. Items are grouped in sets of 12 and arranged into increasing levels of complexity. The basal set rule was one or no errors in a set, and the corresponding ceiling set rule was eight or more errors in a set. Raw scores were converted into standardised scores using an agecorrelated norm table for children in the UK. 
Task

DCCS The DCCS (Zelazo et al. 1996) is a widely used measure of executive function, which has been used extensively in studies on early bilingualism (Bialystok 1999; Bialystok and Martin 2004; Bialystok and Shapero 2005; Carlson and Meltzoff 2008; inter alia). The task requires children to sort a set of cards used as stimuli according to one dimension first, and subsequently reclassify them according to another. For our study, we used the two dimensions of colour and shape, with red and blue alternating with busses and cats. There are two versions - 'standard' and 'border': in the border version, some cards have a border indicating that a switch to the other dimension is required (i.e. if children were classifying objects according to colour and if a card with a border was presented, they had to switch to classifying according to shape). There is a pre- and a post-switch phase for both versions. Normally, for the standard version, 3-year-old children are able to classify the cards correctly into the right category in the pre-switch phase but tend to perseverate with the same dimension during the post-switch phase, regardless of which dimension is presented first. Most children switch immediately when instructed to do so in their 5 th year. The border version, in contrast, may be used with older children up to 7 years, as it provides a more challenging measure of attention to cues and switching. Previous research found that multilingual children pass these tests about one year earlier than monolinguals (Bialystok 1999). Following the Zelazo (2006) protocol, we established the following sequence of phases for assessment, starting always with pre-and post-switch phases of the standard version and, if these were mastered, proceeding to the border version.

Previous studies using the DCCS take a certain number of trials as measure. For example, in Bialystok's (1999) study, children were assigned a score out of 10 for correctly sorted cards in the standard pre-switch phase and a further 10 points for success in the post-switch phase. Finally, a score of 3 was added for success in the border version. However, because the children in our study were older, we decided to dispense with this type of scoring system. Most of our children had been successful in the standard version, as they were older than 3 and we used this as our baseline, but there was great deal of variation in the border version. We found that children were either able to master it or not, in a categorical fashion and with minimal or no hesitation. The question then was whether they would pass the border version or not in a pass/fail dichotomous way, coded as 1 for pass and 0 for fail in our analysis. The order between colour and shape dimensions was alternated between participants (Fig. 2).

\section{Data analysis}

We interpreted our DCCS data as categorical in terms of frequency counts and proportions and applied Pearson's chi-square test to compare numbers of children who passed and who failed at two testing sessions. This was implemented in the CrossTable (Schwartz 2002) package in the R statistical software used in our analysis (R Core Team 2015).

\section{Results}

At the time of the first testing session, all the children involved in the study were older than 3 years and had already mastered the pre-switch phase of the standard version of the DCCS 
Fig. 2 Example of colour (blue and red) and shape (busses and cats) dimensions and standard vs border picture versions used

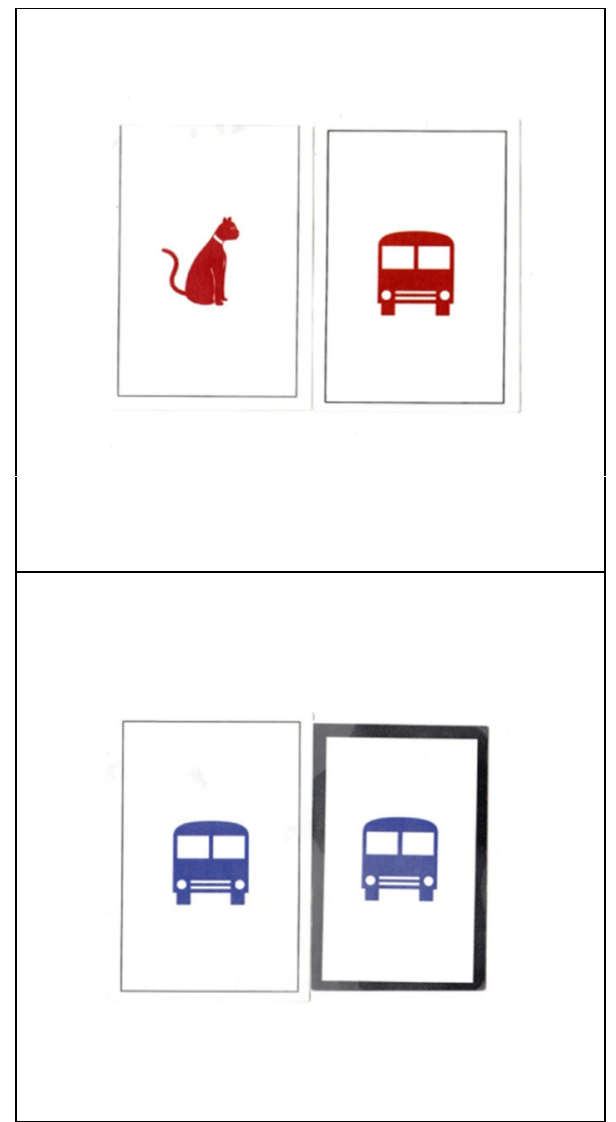

task. Only a small minority (N5), especially among the younger children, had difficulties in passing the post-switch phase of this version. In terms of proportions, we found that the majority of monolingual children (33 out of 36, 91\%) had mastered the standard version of the test and there was what looked like a slight multilingual advantage (24 out of $26,92 \%)$. However, $\chi^{2}$ analysis showed that these proportions bore no statistical significance $\left(\chi^{2}(1)=0.0083, p=0.92\right)$. In contrast, there appeared to be a great deal of variation among individual children in performance for the border version, as a great number failed it (51 out of 62, 82\%). This is consistent with the developmental trend described in Zelazo et al. (1996). On initial examination, it looked like on the surface there was a slight advantage in favour of multilinguals ( 5 out of $26,19 \%$ ) over monolinguals ( 6 out of $36,16 \%$ ). Nevertheless, $\chi^{2}$ analysis again showed that these results were not statistically significant $\left(\chi^{2}(1)=0.068, p=0.79\right)$.

By the second testing session implemented 6 to 8 months later in the language programme intervention, all 62 children involved in the study had mastered the standard version, including children who failed to master it the first time. In contrast, the results for the border version were still varied, but the multilingual advantage trend continued and became more prominent with most ( 24 out of $26,92 \%$ ) of the cohort passing the border version. In contrast, only 17 out of 
$36(47 \%)$ for the monolingual groups passed the more advanced version, as we see from the contingency Table 2 .

A $\chi^{2}$ analysis reveals that there was a significant association between language group (monolingual vs multilingual) and whether children passed the border version or not after the language programme intervention $\left(\chi^{2}(1)=13.70, p=0.0002\right)$, in favour of multilingual children. In other words, our initial hypothesis was supported in that the success in conflict resolution tasks such as DCCS is correlated with the monolingual/multilingual distinction, despite the fact that a great number of our multilingual children had either no or very limited proficiency in English $(\mathrm{M}=$ 81.68, $\mathrm{SD}=10.66$ ).

The second question guiding this research was a comparison of our L1 English speakers or whether there was a difference between L1 English monolinguals in a homogeneous group and L1 English monolinguals in a heterogeneous group: in other words, children who had not had experience with interacting with other multilinguals in the group and those who had, and whether this correlated with cognitive performance.

As we can see from Table 3, although only $47 \%$ of all the children passed the border version of the test, monolingual children in a homogeneous group found themselves at a small disadvantage ( 8 out of $22,36 \%$ ) as opposed to monolinguals in a heterogeneous group (9 out of 14,64\%). $\chi^{2}$ analysis showed there was no significant association between school class group and mastering the border version milestone $\left(\chi^{2}(1)=2.67, p=0.10\right)$, possibly related to the fact that there was an unbalanced number of children in either group $(N=22$ vs $N=14)$; however, there appeared to be a trend where monolingual children in heterogeneous groups found themselves at a slight advantage. However, at this point, we cannot show that this trend is due to the homogeneous/heterogeneous distinction and its effects on classroom dynamics, as there are also other confounding factors.

Table 2 Results for monolingual and multilingual children in the DCCS Border version after language programme intervention

\begin{tabular}{llll}
\hline & Monolinguals & Multilinguals & Row total \\
\hline Fail & & & \\
$\quad$ Count & 19 & 8.806 & 21 \\
Expected values & 12.194 & 5.261 & \\
Chi-square contrib & 3.799 & $9.524 \%$ & $33.871 \%$ \\
Row percent & $90.476 \%$ & $7.692 \%$ & \\
Column percent & $52.778 \%$ & $3.226 \%$ & \\
Total percent & $30.645 \%$ & -2.294 & 41 \\
Std res & 1.949 & 24 & $66.129 \%$ \\
Pass & 17 & 17.194 & \\
Count & 23.806 & 2.694 & \\
Expected values & 1.946 & $58.537 \%$ & 62 \\
Chi-square contrib & $41.463 \%$ & $92.308 \%$ & \\
Row percent & $47.222 \%$ & $38.710 \%$ & \\
Column percent & $27.419 \%$ & 1.641 & \\
Total percent & -1.395 & 26 & \\
Std res & 36 & 0.41935 & \\
Column total & 0.58065 & & \\
& & & \\
\hline
\end{tabular}


Table 3 Results for homogeneous and heterogeneous monolinguals in DCCS Border version after language programme intervention

\begin{tabular}{llll}
\hline & Homogeneous & Heterogeneous & Row total \\
\hline Fail & & & \\
$\quad$ Count & 14 & 5 & 19 \\
Expected values & 11.611 & 7.389 & \\
Chi-square contrib & 0.491 & 0.772 & $52.778 \%$ \\
Row percent & $73.684 \%$ & $35.316 \%$ & \\
Column percent & $63.636 \%$ & $13.889 \%$ & \\
Total percent & $38.889 \%$ & -2.294 & 17 \\
Std res & 1.949 & 9 & \\
Pass & 8 & 6.611 & $47.222 \%$ \\
Count & 10.389 & 0.863 & \\
Expected values & 0.549 & $52.941 \%$ & 36 \\
Chi-square contrib & $47.059 \%$ & $64.286 \%$ & \\
Row percent & $36.348 \%$ & $25.000 \%$ & \\
Column percent & $22.222 \%$ & 0.927 & \\
Total percent & -0.741 & 14 & \\
Std res & 22 & $38.889 \%$ & \\
Column total & $61.111 \%$ & & \\
& & & \\
\hline
\end{tabular}

\section{Discussion}

The results of this study showed that there was a positive association between passing the DCCS task and language group, in favour of multilingual children. There was also an emerging trend indicating that monolinguals in heterogeneous groups performed slightly better than their homogeneous counterparts.

In comparing our results with those of Nicolay and Poncelet's (2013) study, it is interesting to note that our unbalanced multilingual children accrued positive advantages earlier than their immersion counterparts, even with similar levels of English language proficiency. The difference between the two groups of children is both in terms of length of exposure and intensity of language learning experience. Nicolay and Poncelet's children were tested 3 years after having been exposed to another language in an immersion context, whereas the children in our study were involved in a language intervention programme for 6 to 8 months. Another potentially important difference between these two groups, which we can only speculate about here, is that the children in our study may have experienced greater multilingual input intensity, since they were not only receiving input in English language from the environment but also learning Spanish.

Earlier studies concentrated mainly on distinguishing balanced bilinguals from monolinguals, and the results generally showed an advantage in favour of the former. Using the same type of manually administered test we used in our study (i.e. utilising actual cards and sorting trays rather than a computerised version as in Bialystok and Shapero 2005, for example) and both the standard and the border versions, Bialystok (1999) found that younger balanced bilingual children mastered the more advanced border version by age 4 . In addition, her study showed a highly significant different distribution between children who passed and who failed the border (or advanced) version $\left(\chi^{2}(1, N=60)=4.06, p=0.03\right)$. These balanced bilinguals had been exposed to language since birth, and hence, the input experience had been longer and more intense than that of the children we tested, but most crucially, they had been exposed to 
and had been interacting with other multilingual individuals in their close social context from birth. According to Poarch and van Hell (2012), the relative practice in language control and inhibition that bilinguals have experienced and their particular L2 learning paths are responsible for the development of cognitive abilities. They propose a Multilingual Language Continuum based on how much individuals engage in language switching. Bilinguals exposed to languages from birth — who are highly proficient at language switching and inhibition — are placed at one end. At the intermediate level, we find L2 learners exposed to a second language after the age of 3 in immersion programmes and, finally, at the opposite end of the scale are monolingual L2 learners learning a second language in a non-immersion classroom setting.

\section{The Multilingual Language Continuum:}

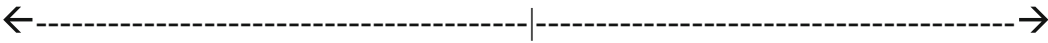 \\ Bilingual from birth Immersion L2 learners Non-immersion L2 learners}

This continuum represents differences in language control and modulation of control during production. Bilingual language control is bidirectional, and this seems to have an effect on the amount of effort children need to control their languages (L1 to L2 and vice versa): especially if they are highly proficient, bilingual children need more effort to control their languages. In contrast, low-proficient L2 learners have been shown to require asymmetric effort in controlling their languages. In this light, according to Poarch and van Hell (2012), it seems that immersion L2 learners are more likely to show cognitive effects than non-immersion L2 learners, as they are more experienced at switching languages. The unbalanced multilingual children in our study would be placed somehow in between the 'bilingual-from-birth' and 'immersion-L2-learners' levels along the continuum: even though they share similar English language proficiency levels, the intensity of the language learning experience puts them in a more advantageous position at an earlier age. As pointed out by Grosjean (2010), language dominance is determined by level of exposure and by intra- and extra-linguistic factors such as the interlocutor, the contextual situation and the communicative function.

The children involved in our language intervention programme had little requirement for language switching, as they belonged to different linguistic backgrounds and, for the most part, the English language featured minimally in their homes. However, they engaged with other children in a highly intensive language learning experience, which combined learning English from the context and learning another language through collaborative activities in the classroom and at home. We can only speculate whether it was the overall intensity of this multiple language learning experience that put these children at an advantage. Already, Hakuta et al. (1987) reported stronger cognitive effects for ab initio learners than for more advanced learners and this was related to the high levels of processing required by individuals when learning a new language. A great number of the multilingual children involved in our intervention programme had only just arrived in the country and were still learning English. It has been said that unbalanced bilinguals often find themselves utilising different working memory strategies and tapping into additional attentional resources to compensate for their limited linguistic abilities (Paradis 2000). With reference to an immersion context, according to Nicolay and Poncelet (2013), children engaging with an L2 environment often have to live 
in a continuous state of processing alertness and, as a result, actually find themselves having to exercise greater cognitive control and executive skills than in a more traditional nonimmersion monolingual school situation. Therefore, it is not surprising that children who have been involved in immersion programmes find themselves at an advantage as the learning experience is likely to be quite intense.

Our results also showed emerging positive trends in terms of pass/fail proportions in favour of monolinguals situated in heterogeneous groups. Even though these results did not reach statistical significance, they are unexpected and worth further exploration. We speculated that they may be related to the fact that, apart from finding themselves involved in a highly intensive language learning experience, these monolingual speakers were also interacting with other multilingual individuals. However, our study had limitations as both our homogeneous and heterogeneous monolingual groups were unbalanced in terms of numbers of children tested. Nevertheless, we believe that future research can design and implement new methods and measures for assessing different types of monolingual speakers to show bilingualism at its very emerging stages, long before we think it is tangible or even measurable. There is no reason to believe that for monolingual children to be placed in such a class is at all detrimental for their development: in fact, it appears to be a positive experience. The emphasis of research so far has been to single out bilinguals from monolinguals, but we now know that not all bilinguals are the same and we contend that this insight can even be applied to L1 monolingual individuals, as not even all of them can be classified under the same rubric. In this context, again, we can cite Grosjean (2010) who believes that just as we are gradually moving away from the notion of the perfect bilingual speaker, we are also moving away from the notion of the ideal monolingual native speaker. Bilingualism is a dynamic process determined by the interaction between individuals engaged in communicative acts and the world. As a result, we need to re-evaluate Poarch and van Hell's (2012) Multilingual Language Continuum and reinterpret the former static bilingual speaker in terms of interaction with other interlocutors in context, rather than in relation to switching and proficiency only. As Unsworth (2016a) mentions, we do not yet fully understand what it means to be bilingual, as there are a great number of factors such as age of onset, quality and quantity of input and attitudes to home languages that contribute to the bilingual experience: thus, we need new ways of analysing these multiple interactions among these factors in different bilingual contexts.

\section{Conclusions}

In this study, we focused on both monolingual and unbalanced multilingual child speakers who were learning other languages. We addressed the question of whether cognitive effects previously found in balanced bilinguals could also be detected in unbalanced bilinguals and monolingual children who find themselves in the context of other bilinguals. To his end, we created an intensive multilingual experience in a non-immersion classroom setting through a language intervention programme, and we measured children's cognitive control abilities at two different stages of the programme. The results showed that a greater number of multilinguals passed the DCCS test than monolinguals, despite low levels of English language proficiency and limited or non-existing language-switching opportunities. Furthermore, we found a slight emerging trend where monolinguals in heterogeneous groups fared better than their homogeneous counterparts. 
This study has limitations in terms of its design, largely due to its exploratory and quasiexperimental nature related to the overall qualitative aims of the SOFT project. First, we would have liked to include more participants especially as some of our groups showed an unbalanced number. Moreover, we did not have a clear control group. Although we took our homogeneous monolingual group to act as our control, it would have been appropriate to make comparisons with other homogeneous monolingual groups who were not involved in the programme, or even a homogeneous multilingual group.

The input provided in the language intervention programme by the Narrative Format Methodology was specifically designed to develop comprehension skills. Language production was limited to repetition, although some basic characteristics of natural dialogue were strictly adhered to. Future research should also evaluate different comprehension and production skills with different types of monolinguals and multilinguals.

However, as it stands, the fact that unbalanced bilinguals/multilinguals and some monolinguals show any effects at all contributes to the debate about what it means to be monolingual, an issue that should not be taken for granted by researchers, as there seem to be as many different types of monolinguals as bilinguals. This is an aspect worth exploring in future research.

Acknowledgements Research for this study was conducted within the SOFT-Project (School and Family Together, for the Integration of Immigrant Children), funded by the European Commission, EACEA, Education and Culture, Lifelong Learning Programme, grant reference number 531208-LLP-1-2012-1-IT-KA2-KA2MP. We are extremely grateful to all the participating parents and children, together with schools and teachers involved in the European SOFT-Project, for their enthusiastic dedication, time and co-operation. We are also extremely grateful to Lesley McDowell, Anne-Marie Procter and Tessa Humbey. We would also like to thank Mariana Vega for her support and invaluable help with our statistical analysis.

Compliance with ethical standards The study was approved by the Linguistics and English Language ethics committee at the University of Edinburgh.

\section{Appendix. Sample of Narrative Format Methodology story involving dialogues and songs implemented throughout the programme}

\section{Format 1}

\section{Introduction}

Children and tutor together count from 1 to 10 in Spanish, holding hands.

Narratives (dialogues and songs)

Spanish: Habia una vez un huevo y dentro del huevo estaba Hocus.

English: Once upon a time, there was an egg and inside the egg was Hocus.

Spanish: Croc, Croc... sssss, iijescuchad!!! ¿Qué es? ¡Hola!!

English: Crock, crock... shhhhh, listen!!! What's that? Hello!!

Spanish: Un día estaba Hocus paseando por el parque... Tralaralara, Tralaralara.

English: One day, Hocus was walking in the park... tralaralara, tralaralara.

Spanish: Chip, chip, chip, chip...Soy un pájaro.

English: Chip, chip, chip, chip... I'm a bird.

Spanish: Yo también soy un pájaro. 
English: I'm a bird too.

Spanish: ¿Tú, un pájaro? No, tú no eres un pájaro, Adios....

English: You, a bird? No, you are not a bird. Bye, bye....

(Singing)

Spanish: Adios, Tralaralara, Tralaralara.

English: Bye, bye, tralaralara, tralaralara.

Spanish: Cua, сиа, сиа, сиа ... Soy un pato.

English: Cua, cua, cua, cua ... I'm a duck.

Spanish: Yo también soy un pato.

English: I'm a duck too.

Spanish: ¿Tú, un pato? No, tú no eres un pato, Adios....

English: You, a duck? No, you are not a duck. Bye, bye....

Spanish: Crua, crua, crua, crua ....

English: Crua, crua, crua, crua ... I'm a frog.

Open Access This article is distributed under the terms of the Creative Commons Attribution 4.0 International License (http://creativecommons.org/licenses/by/4.0/), which permits unrestricted use, distribution, and reproduction in any medium, provided you give appropriate credit to the original author(s) and the source, provide a link to the Creative Commons license, and indicate if changes were made.

\section{References}

Abbot-Smith, K., \& Tomasello, M. (2006). Exemplar learning and schematization in a usage-based account of syntactic acquisition. The Linguistic Review, 23, 275-290.

Bialystok, E. (1999). Cognitive complexity and attentional control in the bilingual mind. Child Development, $70(3), 636-644$.

Bialystok, E., \& Feng, X. (2009). Language proficiency and executive control in proactive interference: evidence from monolingual and bilingual children and adults. Brain and Language, 109(23), 93-100.

Bialystok, E., \& Martin, M. (2004). Attention and inhibition in bilingual children: evidence from the dimensional change card sort task. Developmental Science, 7(3), 325-339.

Bialystok, E., \& Shapero, D. (2005). Ambiguous benefits: the effects of bilingualism on reversing ambiguous figures. Developmental Science, 8(6), 595-604.

Bialystok, E., Peets, K., \& Moreno, S. (2014). Producing bilinguals through immersion education: development of metalinguistic awareness. Applied Psycholinguist, 35(1), 177-191.

Carlson, S., \& Meltzoff, A. (2008). Bilingual experience and executive functioning in young children. Developmental Science, 11(2), 282-298.

Cummings, J. (2012). The intersection of cognitive and sociocultural factors in the development of reading comprehension among immigrant students. Reading and Writing, 25(8), 1973-1990.

de Houwer, A. (2009). Bilingual first language acquisition. Multilingual Matters: Clevedon.

de Houwer, A., \& Bornstein (2003): Balancing on the tightrope: language use patterns in bilingual families with young children. Paper presented at the Meeting of the Fourth International Symposium on Bilingualism, Temp, Arizona.

Deák, G. O. (2014). Interrelations of language and cognitive development. In P. Brooks \& V. Kampe (Eds.), Encyclopaedia of language development (pp. 284-291). London: Sage.

Dunn, L. M., Dunn, D. M., Styles, B., \& Sewell, J. (2009). The British picture vocabulary scale III (3rd ed.). London: GL Assessment.

Garraffa, M., Beveridge, M., \& Sorace, A. (2015). Linguistic and cognitive skills in Sardinian-Italian bilingual children. Frontiers in Psychology, 6, [1898]. https://doi.org/10.3389/fpsyg.2015.01898

Goldberg, A. (2003). Constructions: a new theoretical approach to language. TRENDS in Cognitive Science, 7(5), $219-224$. 
Green, D., \& Abutalebi, J. (2013). Language control in bilinguals: the adaptive control hypothesis. Journal of Cognitive Psychology, 25(5), 515-530.

Grosjean, F. (2010). Bilingual life and reality. Harvard: Harvard University Press.

Hakuta, K., Ferdman, B. M., \& Diaz, R. M. (1987). Bilingualism and cognitive development: Three perspectives. In S. Rosenberg (Ed.), Cambridge monographs and texts in applied psycholinguistics. Advances in applied psycholinguistics, Vol. 1. Disorders of first-language development; Vol. 2. Reading, writing, and language learning (pp. 284-319). New York, NY, US: Cambridge University Press.

Luk, G., De Sa, E., \& Bialystok, E. (2011). Is there a relation between onset of the age of bilingualism and enhancement of cognitive control? Bilingualism: Language and Cognition, 14(4), 588-595.

Nicolay, A., \& Poncelet, M. (2013). Cognitive advantage in children enrolled in second-language immersion elementary school program for three years. Bilingualism: Language and Cognition, 16(3), 597-607.

Paap, K. R., \& Greenberg, Z. I. (2013). There is no coherent evidence for a bilingual advantage in executive processing. Cognitive Psychology, 66(2), 232-258.

Paap, K. R., \& Sawi, O. (2014). Bilingual advantages in executive functioning: problems in convergent validity, discriminant validity and the identification of the theoretical constructs. Frontiers in Psychology, 5, 962.

Paap, K. R., Johnson, H. A., \& Sawi, O. (2014). Are bilingual advantages dependent upon specific tasks or specific bilingual experiences? Journal of Cognitive Psychology, 26(6), 615-639.

Paradis, M. (2000). Aphasie chez les bilingues et les multilingues. In J. A. Rondal \& X. Seron (Eds.), Troubles du langage: bases théoriques, diagnostic et rééducation (pp. 530-549). Liège: Mardaga.

Place, S., \& Hoff, E. (2011). Properties of dual language exposure that influence 2-year-olds' bilingual proficiency. Child Development, 82(6), 1834-1849.

Poarch, G., \& van Hell, J. (2012). Executive functions and inhibitory control in multilingual children: evidence from second language learners, bilinguals and trilinguals. Journal of Experimental Child Psychology, 111(3), $419-438$

R Core Team (2015). R: a language and environment for statistical computing. R Foundation for Statistical Computing, Vienna, Austria. URL https://www.R-project.org/.

Sabbah, M. A., Xu, F., Carlson, S. M., \& Moses, L. J. (2006). The development of executive functioning and theory of mind: a comparison of Chinese and US pre-schoolers. Psychological Science, 17(1), 74-81.

Schwartz, M. (2002). Cross tabulation with tests for factor independence. R Package Version 0.99.879.

Taeschner, T. (2005). The magic teacher: learning a foreign language at nursery school. Results from the project. London: CILT.

Tomasello, M. (2003). Constructing a language: a usage-based theory of language acquisition. Cambridge: Harvard University Press.

Unsworth, S. (2014). Comparing the role of input and experience in bilingual acquisition across domains. In Input and experience in bilingual development. Amsterdam: John Benjamin.

Unsworth, S. (2016a). Quantity and quality of language input in bilingual language development. In E. Nicoladis \& S. Montanari (Eds.), Bilingualism across the lifespan: factors moderating language proficiency (pp. 136196). Washington DC: Mouton de Gruyter, American Psychological Association.

Unsworth, S. (2016b). Early child L2 acquisition: age or input effects? Neither, or both? Journal of Child Language, 43(3), 603-634.

Zelazo, D. (2006). The dimensional change card sort: a method of assessing executive function in children. Nature Protocols, 1(1), 297-301.

Zelazo, D., Frye, D., \& Rapus, T. (1996). An age-related dissociation between knowing rule and using them. Cognitive Development, 11(1), 37-63.

Dr. Martha G. Robinson is a theoretical linguist and a researcher into language and cognition with a particular interest in early unbalanced multilingualism and integration in education. She is currently a research assistant in Developmental Linguistics at the University of Edinburgh and a volunteer at the information and consultancy centre Bilingualism Matters, University of Edinburgh.

Prof. Antonella Sorace is an experimental linguist, specializing in bilingualism across the lifespan. She is currently Professor of Developmental Linguistics at the University of Edinburgh, Director and founding member of the information and consultancy centre Bilingualism Matters, University of Edinburgh. 